\title{
Size-resolved chemical composition, effective density, and optical properties of biomass burning particles
}

\author{
Jinghao Zhai ${ }^{1}$, Xiaohui Lu ${ }^{1}$, Ling Li ${ }^{1}$, Qi Zhang ${ }^{1,2}$, Ci Zhang ${ }^{1}$, Hong Chen ${ }^{1}$, Xin Yang ${ }^{1}$, and Jianmin Chen ${ }^{1}$ \\ ${ }^{1}$ Shanghai Key Laboratory of Atmospheric Particle Pollution and Prevention, Department of Environmental Science \\ and Engineering, Fudan University, Shanghai 200433, China \\ ${ }^{2}$ Department of Environmental Toxicology, University of California, Davis, California 95616, USA
}

Correspondence to: Xin Yang (yangxin@ fudan.edu.cn)

Received: 28 November 2016 - Discussion started: 7 December 2016

Revised: 21 April 2017 - Accepted: 22 May 2017 - Published: 21 June 2017

\begin{abstract}
Biomass burning aerosol has an important impact on the global radiative budget. A better understanding of the correlations between the mixing states of biomass burning particles and their optical properties is the goal of a number of current studies. In this work, the effective density, chemical composition, and optical properties of rice straw burning particles in the size range of $50-400 \mathrm{~nm}$ were measured using a suite of online methods. We found that the major components of particles produced by burning rice straw included black carbon (BC), organic carbon (OC), and potassium salts, but the mixing states of particles were strongly size dependent. Particles of $50 \mathrm{~nm}$ had the smallest effective density $\left(1.16 \mathrm{~g} \mathrm{~cm}^{-3}\right)$ due to a relatively large proportion of aggregate BC. The average effective densities of 100 $400 \mathrm{~nm}$ particles ranged from 1.35 to $1.51 \mathrm{~g} \mathrm{~cm}^{-3}$ with OC and inorganic salts as dominant components. Both density distribution and single-particle mass spectrometry showed more complex mixing states in larger particles. Upon heating, the separation of the effective density distribution modes confirmed the external mixing state of less-volatile BC or soot and potassium salts. The size-resolved optical properties of biomass burning particles were investigated at two wavelengths $(\lambda=450$ and $530 \mathrm{~nm})$. The single-scattering albedo (SSA) showed the lowest value for $50 \mathrm{~nm}$ particles $(0.741 \pm 0.007$ and $0.889 \pm 0.006)$ because of the larger proportion of BC content. Brown carbon played an important role for the SSA of 100-400 nm particles. The Ångström absorption exponent (AAE) values for all particles were above 1.6 , indicating the significant presence of brown carbon in all sizes. Concurrent measurements in our work provide a basis for discussing the physicochemical properties of biomass
\end{abstract}

burning aerosol and its effects on the global climate and atmospheric environment.

\section{Introduction}

Biomass burning is a significant source of trace gases and aerosol particles (Andreae and Merlet, 2001). Biomass burning particles affect climate by both absorbing and scattering solar radiation (Chand et al., 2009) and serve as cloud condensation nuclei that modify cloud microphysical properties (Petters et al., 2009). In addition, biomass burning particles have considerable impacts on air quality, regional visibility, and human health (Naeher et al., 2007; Park et al., 2006). Global annual emissions of black carbon (BC) and organic carbon (OC) aerosols are estimated to be $\sim 8$ and 33.9 $\mathrm{Tg} \mathrm{yr}^{-1}$, while open burning contributes approximately $42 \%$ for BC and $74 \%$ for OC (Bond et al., 2004). Along with rapid economic development and an increase in agricultural activities, emissions from agricultural residue combustion in China have drawn extensive attention. The total amount of straw used for open burning in China is estimated to be $\sim 140 \mathrm{Tg} \mathrm{yr}^{-1}$ (Cao et al., 2008).

The mixing state, composition, and morphology of particles can influence their radiative properties. BC, which is predominantly produced from combustion-related sources, absorbs solar radiation across the visible spectrum, resulting in a warming effect (Bond et al., 2013). The co-emission of $\mathrm{BC}$ and $\mathrm{OC}$ can lead to internally mixed particles; the OC coating can enhance particle absorption through lensing effects (Bond and Bergtrom, 2006; Schnaiter et al., 2005). 
Some organic matter containing specific functional groups (e.g., nitrated or polycyclic aromatics, phenols) can absorb radiation itself in the short-wavelength visible and UV wavelengths (Hoffer et al., 2006; Jacobson, 1999) and is referred to as brown carbon $(\mathrm{BrC})$. As biomass burning is a significant source of $\mathrm{BrC}$, the optical properties of biomass burning particles need to be further understood. Field work has been conducted to measure the light absorption enhancement by particle coatings in different areas (Chan et al., 2011; Nakayama et al., 2014). The degree to which particles absorb light depends on their composition, shape, and mixing state. Research on the chemical composition and mixing state of biomass burning particles has been previously carried out by our group members (Huo et al., 2016; Zhai et al., 2015). However, it remains unclear how the mixing states and chemical composition of biomass burning particles influence their morphology and optical properties.

Particles emitted from biomass burning are generally composed of a mixture of spherical and nonspherical particles and chain aggregates (Martins et al., 1998). Scanning electron microscopy (SEM) and transmission electron microscopy (TEM) are common techniques widely used to investigate the morphology of biomass burning particles (China et al., 2013; Giordano et al., 2015; Hopkins et al., 2007). However, these methods are unable to provide continuous "online" information and suffer from limitations arising from primary particle overlap, screening effects, and cluster anisotropy (Wentzel et al., 2003). Effective density is a good predictor of the complex properties of biomass burning particles (Pitz et al., 2008) and is often used to convert particle size distributions into mass loading (Schmid et al., 2007). Variations in particle effective density can be used to follow compositional transformations during chemical reactions (Katrib et al., 2005). Online measurements that provide real-time monitoring of particle effective density variation have been developed. Kelly and McMurry (1992) developed a density measurement technique based on the selection of a monodisperse aerosol with a differential mobility analyzer (DMA) followed by classification according to aerodynamic diameter with an impactor. McMurry et al. (2002) reported a technique to determine size-resolved effective density using an aerosol particle mass analyzer (APM) to measure the mass of particles that had been classified according to electrical mobility by a DMA. The DMA-APM method has been applied extensively in field studies as well as laboratory experiments (Hu et al., 2012; Barone et al., 2011). However, few measurements of the effective density of biomass burning particles have been taken due to the lack of accompanying online chemical information.

The mixing state of individual particles can be very different due to factors such as the chemical composition and aging degree, which greatly influence the morphology and optical property of particles. Thus, distinctions among particles might be omitted by bulk measurements. Single-particle mass spectrometry techniques have been utilized to measure

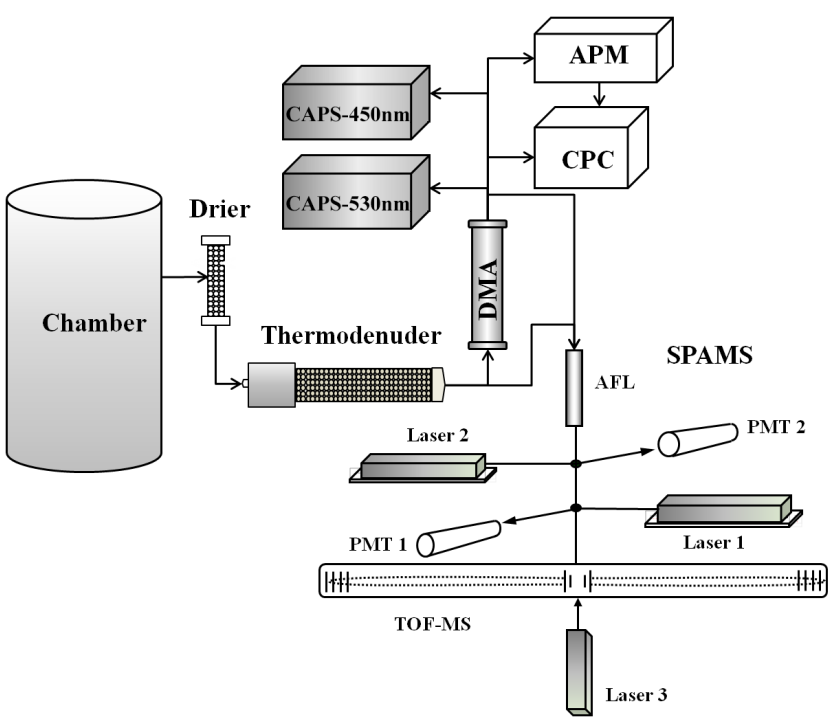

Figure 1. Schematic of the instrumental setup. CAPS, DMA, CPC, APM, and SPAMS represent cavity attenuated phase shift spectroscopy, differential mobility analyzer, condensation particle counter, aerosol particle mass analyzer, and single-particle aerosol mass spectrometer, respectively.

the chemical composition, size, density, and shape of individual particles. Spencer et al. (2007) utilized a system incorporating DMA and an ultrafine aerosol time-of-flight mass spectrometer (UF-ATOFMS) to simultaneously detect the effective density and chemical composition of ambient aerosol at the single-particle level. Such comprehensive information about single particles could help to elucidate the morphology, mixing state, and sphericity of biomass burning particles.

The chemical composition, morphology, and optical properties of particles are usually interrelated. A biomass burning particle is a complex mixture of organic and inorganic species, including strongly light-absorbing $\mathrm{BC}$ and $\mathrm{BrC}$. Size-resolved or even single-particle-level information on the morphology, chemical composition, and optical properties of biomass burning particles is necessary for a better understanding of the correlations among these physicochemical properties. In this study, laboratory experiments were conducted on rice straw combustion, a main source of biomass burning particles in southern China. The size-resolved effective density of biomass burning particles was measured by two different methods. One was based on a DMA-APM coupled with a condensation particle counter (CPC) system. For the other method, the mobility-size-selected particles by a DMA were transported into a single-particle aerosol mass spectrometer (SPAMS), where the vacuum aerodynamic diameter and chemical composition of individual particles were measured. The size-resolved optical properties of biomass burning particles were also measured by cavity attenuated phase shift spectroscopy (CAPS). A thermodenuder (TD) was used to help analyze the mixing state of particles 
by removing the volatile compounds and leaving behind the less-volatile species based on the vaporization temperature of the materials. The purpose of our study was to add physicochemical knowledge regarding biomass burning particles, which is an important aerosol source globally.

\section{Experiments}

\subsection{Laboratory-made biomass burning particles}

Rice straw, a typical type of crop residue in southern China, was taken as the representative biomass burning material in our experiment. The self-designed combustion setup was introduced in previous work (Huo et al., 2016). Rice straw collected in rural residential areas in Shanghai was dehydrated for $24 \mathrm{~h}$ at $100^{\circ} \mathrm{C}$ in an oven prior to combustion. Five replicate tests of straw burning were conducted for each experiment. For each test, $\sim 50 \mathrm{~g}$ of dried rice straw was burned in a combustion stove. The emitted smoke was introduced into a $4.5 \mathrm{~m}^{3}$ (in volume) chamber with a flow rate of $50 \mathrm{~L} \mathrm{~min}^{-1}$. Ambient air was introduced though a high-efficiency particulate air filter to maintain the ambient pressure. The particles in the chamber were then introduced into the measurement system through a silica gel diffusion drier (shown in Fig. 1).

\subsection{Single-particle mass spectrometry}

A single-particle aerosol mass spectrometer (SPAMS; Hexin Analytical Instrument Co., Ltd) was deployed to examine the aerosol chemical composition and aerodynamic diameter at the single-particle level. Detailed information on the SPAMS has been described elsewhere (Li et al., 2011). Particles in the size range of $0.2-2.0 \mu \mathrm{m}$ are first drawn into the vacuum through an aerodynamic focusing lens. Each particle is accelerated to a size-dependent aerodynamic velocity, which is calculated based on two orthogonally oriented continuous lasers (Nd: YAG; $532 \mathrm{~nm}$ ). The two lasers are fixed at a $6 \mathrm{~cm}$ distance and the delay of the scatter light is collected by two photomultiplier tubes (PMTs). When a particle arrives at the ion source region, a pulsed desorption-ionization laser (Qswitched Nd:YAG; $266 \mathrm{~nm}$ ) is triggered. Ions are recorded by a bipolar time-of-flight spectrometer, which records both positive and negative mass spectra for each single particle. In this work, the power of the desorption-ionization laser was set to $\sim 0.6 \mathrm{~mJ}$ per pulse. The aerodynamic diameter measurement is calibrated with curves generated by monodisperse polystyrene latex spheres (Nanosphere Size Standards; Duke Scientific Corp.) with known diameters $(0.2-2.0 \mu \mathrm{m})$.

All single-particle mass spectra acquired were converted to a list of peaks at each $\mathrm{m} / \mathrm{z}$ by setting a minimum signal threshold of 30 arbitrary units above the baseline with TSI MS-Analyze software. The resulting peak lists together with other SPAMS data were imported into YAADA (version 2.11; www.yaada.org), a software toolkit for single-particle data analysis written in MATLAB (version R2011b). In this work, a total of 10220 biomass burning particles were chemically analyzed according to their positive and negative ion spectra, accounting for about $48 \%$ of all particles. According to the similarities of the mass-to-charge ratio and peak intensity, the biomass burning particles were classified using a clustering method based on adaptive resonance theory (ART-2a; Song et al., 1999). Based on previous work (Huang et al., 2013; Spencer et al., 2007), the parameters for ART-2a used in this work, such as vigilance factor, learning rate, and iterations, were $0.85,0.05$, and 20 , respectively. The particle clusters resulting from ART-2a were then grouped into six particle types based on the mass spectral patterns and chemical similarities. The name of a particle type reflects the dominant chemical species.

\subsection{Effective density measurements}

\subsubsection{Theoretical calculation and methods}

Particle density $\left(\rho_{\mathrm{p}}\right)$ is referenced to the volume equivalent diameter $\left(d_{\mathrm{ve}}\right)$, which is defined as the diameter of a spherical particle with the same volume as the particle under consideration. Particle density can be derived as follows, where $m_{\mathrm{p}}$ is the particle mass:

$$
\rho_{\mathrm{p}}=\frac{m_{\mathrm{p}}}{\frac{\pi}{6} d_{\mathrm{ve}}^{3}} .
$$

When particles are not spherical, the "effective density", which is not necessarily a true measurement of particle density, is derived. Various definitions of effective density are provided in the literature, and a review of these definitions is given by DeCarlo et al. (2004). Different definitions may aim to present different values for a given particle. It is important to understand the derivation, calculation, and measurement for one method of particle effective density.

\section{DMA-APM-CPC system}

The effective density of a particle can be calculated by combining mobility and mass measurements under the assumption that the particle is spherical; thus, its physical diameter is equal to the electrical mobility diameter $\left(d_{\mathrm{m}}\right)$ measured by a DMA. The effective density $\left(\rho_{\text {eff }}^{\mathrm{I}}\right)$ can be calculated with the following equation:

$\rho_{\mathrm{eff}}^{\mathrm{I}}=\frac{m_{\mathrm{p}}}{\frac{\pi}{6} d_{\mathrm{m}}^{3}}$,

where $m_{\mathrm{p}}$ stands for the particle mass obtained by an APM. In our work, we selected biomass burning particles with mobility diameters of 50,100, 200, and $400 \mathrm{~nm}$ and determined their effective density using the DMA-APM-CPC system.

\section{DMA-SPAMS system}

Another approach to deriving effective density is through a combination of mobility and aerodynamic measurements. Si- 
multaneously measuring the particle electrical mobility diameter $\left(d_{\mathrm{m}}\right)$ by DMA and the vacuum aerodynamic diameter $\left(d_{\mathrm{va}}\right)$ by SPAMS allows for the determination of particle effective density $\left(\rho_{\text {eff }}^{\mathrm{II}}\right)$ with the following equation:

$\rho_{\mathrm{eff}}^{\mathrm{II}}=\frac{d_{\mathrm{va}}}{d_{\mathrm{m}}} \rho_{0}$,

where $\rho_{0}$ is the standard density $\left(1.0 \mathrm{~g} \mathrm{~cm}^{-3}\right)$. In this study, since particles smaller than $200 \mathrm{~nm}$ may not scatter sufficient light to be detected by SPAMS and the number concentration of biomass burning particles above $400 \mathrm{~nm}$ was low (shown in Fig. S1 in the Supplement), we selected 200 and $400 \mathrm{~nm}$ particles by DMA and then introduced them into SPAMS.

\section{Shape factor calculation}

The shape of particles can influence the optical properties and can reflect the mixing state of particles to some degree. It is possible to extract the shape information based on the measurements above.

The relationship between the volume equivalent diameter $\left(d_{\mathrm{ve}}\right)$ and mobility diameter $\left(d_{\mathrm{m}}\right)$ is shown in the following equation:

$$
\frac{d_{\mathrm{m}}}{C_{c}\left(d_{\mathrm{m}}\right)}=\frac{d_{\mathrm{ve}} \chi}{C_{c}\left(d_{\mathrm{ve}}\right)}
$$

where $\chi$ is the shape factor, or the ratio of the resistance force on the nonspherical particle to the resistance force on its volume equivalent sphere (Hinds, 1999). The $\chi$ value equals 1 for spherical particles and is greater than 1 for nonspherical and irregular particles.

$\mathrm{Cc}$ is the Cunningham slip correction factor parameterized as

$\mathrm{Cc}(d)=1+\frac{2 \lambda}{d}\left[\alpha+\beta \exp \left(-\gamma \frac{d}{2 \lambda}\right)\right]$,

where $d$ is the particle diameter $\left(d_{\mathrm{m}}\right.$ or $\left.d_{\mathrm{ve}}\right)$ and $\lambda$ is the mean free path of gas molecules. The empirical constants $\alpha, \beta$, and $\gamma$ are $1.142,0.558$, and 0.999 , respectively (Allen and Raabe, 1985).

The vacuum aerodynamic diameter $\left(d_{\mathrm{va}}\right)$ is related to the volume equivalent diameter $\left(d_{\mathrm{ve}}\right)$ by

$d_{\mathrm{va}}=\frac{\rho_{\mathrm{p}}}{\rho_{0}} \frac{d_{\mathrm{ve}}}{\chi}$.

As the measurements of mobility and aerodynamic diameters are readily available, we assumed the error was in the particle mass measurement if the measured $\rho_{\text {eff }}^{\text {II }}$ is used to replace $\rho_{\text {eff }}^{\mathrm{I}}$ in Eq. (2) (Decarlo et al., 2004). With assumed particle density $\left(\rho_{\mathrm{p}}\right)$ and known particle mass $\left(m_{\mathrm{p}}\right)$ measured by an APM, a calculated $d_{\mathrm{ve}}$ could be obtained using Eq. (1). Though $\rho_{\mathrm{p}}$ was unknown, it would be canceled out later. Using the same $d_{\mathrm{ve}}$ for any shape factor $(\chi)$, calculated values for $d_{\mathrm{m}}$ and $d_{\mathrm{va}}$ were obtained with Eqs. (4) and (6), respectively. Thus, $\rho_{\text {eff }}^{\mathrm{II}}$ could be obtained from the calculated $d_{\mathrm{m}}$ and $d_{\mathrm{va}}$ and an estimated $m_{\mathrm{p}}$ was calculated by replacing $\rho_{\text {eff }}^{\mathrm{I}}$ by $\rho_{\text {eff }}^{\mathrm{II}}$ in Eq. (2). We then calculated the ratio of the estimated $m_{\mathrm{p}}$ to the exact $m_{\mathrm{p}}$ as a function of $d_{\mathrm{m}}$ and $\chi$ (shown in Fig. S4; discussed in Sect. 3.1.5).

\subsubsection{Instrumentation for effective density measurements}

The size distribution of biomass burning particles was detected by a scanning mobility particle sizer (SMPS) consisting of a differential mobility analyzer (DMA; model 3080; TSI Inc.) and a condensation particle counter (CPC; model 3775; TSI Inc.). An aerosol particle mass analyzer (APM; model 3601; Kanomax Inc.) was used to classify aerosol particles according to their mass-to-charge ratio. The detailed information of the APM classification principle was previously reviewed by Tajima et al. (2011). Particles were size selected by DMA after being charged with a $\mathrm{Kr}-85$ neutralizer. Particles with a known size were then introduced into APM. When the radial electrical and centrifugal forces were in balance, particles passed through the rotating cylinders to CPC. Mass distribution was obtained by voltage scanning and particle counting.

\subsection{Optical measurements}

Cavity attenuated phase shift (CAPS) spectroscopy (Shoreline Science Research Inc.) was used to determine the particle extinction and scattering coefficient. Detailed information on the CAPS is available in Onasch et al. (2015). A square-wave modulated light-emitting diode (LED) is transmitted through an optical cavity cell. A sample cell incorporating two high-reflectivity mirrors $(R \sim 0.9999)$ with a vacuum photodiode detector (Hamamatsu R645) centers at the wavelength of the LED. The particle extinction coefficient $\left[b_{\text {ext }}(\lambda)\right]$ can be obtained from the changes in the phase shift of the distorted waveform of the LED. An integrating nephelometer with an integrating sphere $10 \mathrm{~cm}$ in diameter is operated to measure the scattering coefficient $\left[b_{\text {scat }}(\lambda)\right]$. Particles are illuminated by the collimated light beam that has measured the extinction. The scattered light of particles is collected at all angles by the integrating sphere. A PMT (H7828-01; Hamamatsu) with a high-voltage power supply and an amplifier records the scattered light. In this work, we used two CAPSs with the LED light sources at wavelengths of 450 and $530 \mathrm{~nm}$ to detect the optical properties of biomass burning particles, respectively.

\subsection{Thermodenuder}

A thermodenuder (TD; model 3065; TSI Inc.) was utilized to separate volatile and less-volatile species of biomass burning particles at specific temperatures. The TD consists of a $40 \mathrm{~cm}$ long desorber section and a $70 \mathrm{~cm}$ long adsorption tube. The 
sample can be heated up to $400^{\circ} \mathrm{C}$ in the desorber section; we selected 150 and $300{ }^{\circ} \mathrm{C}$ in this work. The adsorption tube is surrounded by an annular bed of activated carbon, which adsorbs the evaporated gas-phase compounds, leaving behind the less-volatile fractions. With a flow rate of $0.6 \mathrm{~L} \mathrm{~min}^{-1}$, the residence time of particles in the TD heating section was approximately $9 \mathrm{~s}$.

The particle number fractions after heating do not necessarily represent the actual number fractions before heating as some of the particles can evaporate completely. Particle loss could also be produced in the TD heating or adsorption section due to thermophoretic forces and diffusion, respectively (Philippin et al., 2004). On account of the quantitative measurements of optical properties, particle loss could lead to the underestimation of $b_{\text {ext }}$ and $b_{\text {scat }}$.

Sodium chloride $(\mathrm{NaCl})$ aerosol produced by a single-jet atomizer (model 9302; TSI Inc.) was used to determine the transport efficiency $(\eta)$ in TD. The transport efficiencies of $\mathrm{NaCl}$ at different electrical mobility diameters selected by DMA $\left(d_{\mathrm{m}}: 50,100,200\right.$, and $\left.400 \mathrm{~nm}\right)$ at a range of temperatures $\left(T_{i}: 20,150\right.$, and $\left.300^{\circ} \mathrm{C}\right)$ are shown in Fig. S2. In TD, $\eta$ decreased with increasing $T_{i}$ and decreasing $d_{\mathrm{m}}$, which is consistent with the result in Philippin et al. (2004). The measured $\eta$ values were used to correct the particle number concentration in the calculation of all the measurements related to the thermo-denuding process.

\section{Results and discussion}

\subsection{Size-resolved effective density}

\subsubsection{Effective density from DMA-APM-CPC measurements $\left(\rho_{\text {eff }}^{\mathrm{I}}\right)$}

The effective density of particles, measured using the DMAAPM-CPC system $\left(\rho_{\text {eff }}^{\mathrm{I}}\right)$, provided useful information on the mixing state of particles. A Gaussian model was applied to determine the effective densities of the biomass burning particles selected by DMA (shown in Fig. 2). The density distribution of $50 \mathrm{~nm}\left(d_{\mathrm{m}}\right)$ particles showed a single-peak profile with a peak value of $1.17 \mathrm{~g} \mathrm{~cm}^{-3}$ (Table S1). Two possible factors could be inferred from this feature: a nearly monodisperse aerosol effective density distribution or a juncture of two modes with very close peak values. Biomass burning particles contain highly agglomerated structures like soot (Martins et al., 1998). Although the material density of black carbon (BC) is $\sim 1.8 \mathrm{~g} \mathrm{~cm}^{-3}$ (Bond and Bergstrom, 2006), fresh $\mathrm{BC}$ particles with an aggregate structure can have an effective density less than $1.0 \mathrm{~g} \mathrm{~cm}^{-3}$ (Rissler et al., 2014). The density of organic matter varies in the range of 1.2 $2.0 \mathrm{~g} \mathrm{~cm}^{-3}$ depending on sources (Hand et al., 2010; Turpin and Lim, 2001). Since particles of $50 \mathrm{~nm}$ have the possibility of containing organic matter rather than $\mathrm{BC}$ alone, the apparent single-peak density distribution of these particles was more likely due to the combination of two modes representing $\mathrm{BC}$ and organic particles, respectively (the dashed lines shown in Fig. 2). The thermal desorption method can help to explain the mixing state of $50 \mathrm{~nm}$ particles, which will be discussed in Sect. 3.1.3.

The density distribution of $100 \mathrm{~nm}$ particles exhibited a peak at $1.45 \mathrm{~g} \mathrm{~cm}^{-3}$ at room temperature, which suggests that these particles were dominated by organic matter. However, less-massive composition with an effective density of $0.9-1.1 \mathrm{~g} \mathrm{~cm}^{-3}$ was also obtained for $100 \mathrm{~nm}$ particles. This range is identical to the density of fresh $\mathrm{BC}$ with an aggregate structure. The bimodal distribution of the density profile of $100 \mathrm{~nm}$ particles suggests that BC was partly externally mixed with other components in ultrafine particles from biomass burning emissions. Similar results have been found by Lack et al. (2012) and Adachi and Buseck (2011). The external mixing of $\mathrm{BC}$ and organic particulate matter was evident in the density distribution of $200 \mathrm{~nm}$ particles as well (Fig. 2). For $400 \mathrm{~nm}$ particles, in addition to a dominant density mode at $1.34 \mathrm{~g} \mathrm{~cm}^{-3}$, a relatively weak mode with an effective density of $1.92 \mathrm{~g} \mathrm{~cm}^{-3}$ was observed. Previous studies have shown that potassium chloride crystals, which have a material density of $\sim 1.99 \mathrm{~g} \mathrm{~cm}^{-3}$ (Lide, 2008), were observed in the TEM of fresh biomass burning particles ( $\mathrm{Li}$ et al., 2015). Evidence of the external mixing of sodium and potassium salts in the ambient environment was also observed by single-particle mass spectrometry in previous work (Zauscher et al., 2013; Bi et al., 2011). Recent work performed by Lee et al. (2016) reported that $\mathrm{K}^{+}$was not uniformly mixed in biomass burning particles with less than $20 \%$ of particles containing a high $\mathrm{K}^{+}$content. Thus, we estimate that the mode at $1.92 \mathrm{~g} \mathrm{~cm}^{-3}$ was associated with $\mathrm{KCl}$, and possibly $\mathrm{KSO}_{4}$ and $\mathrm{KNO}_{3}$, and that these crystalline species were more likely externally mixed with organic matter in biomass burning particles. Similar results for the externally mixed aerosol population were observed by Moffet et al. (2008) with a wide range of densities $\left(1.1-3.4 \mathrm{~g} \mathrm{~cm}^{-3}\right)$.

Though freshly emitted, biomass burning particles can be pronouncedly coated by secondary species, such as ammonium nitrate and ammonium sulfate, in a very short period (Leskinen et al., 2007). The bulk density of both ammonium nitrate and ammonium sulfate is $\sim 1.75 \mathrm{~g} \mathrm{~cm}^{-3}$. The differences in the peak values of the dominant mode observed for $50-400 \mathrm{~nm}$ particles are associated with the composition and morphology of particles. Different proportions of the same material can lead to differences in particle effective density. The dominant modes for biomass burning particles in the size range of 50-400 nm (Fig. 2) could be a mixture of similar composition (BC, OC, potassium salts, and secondary inorganic species) but different proportions. Detailed information and a discussion about the particle composition can be found in Sect. 3.2. 

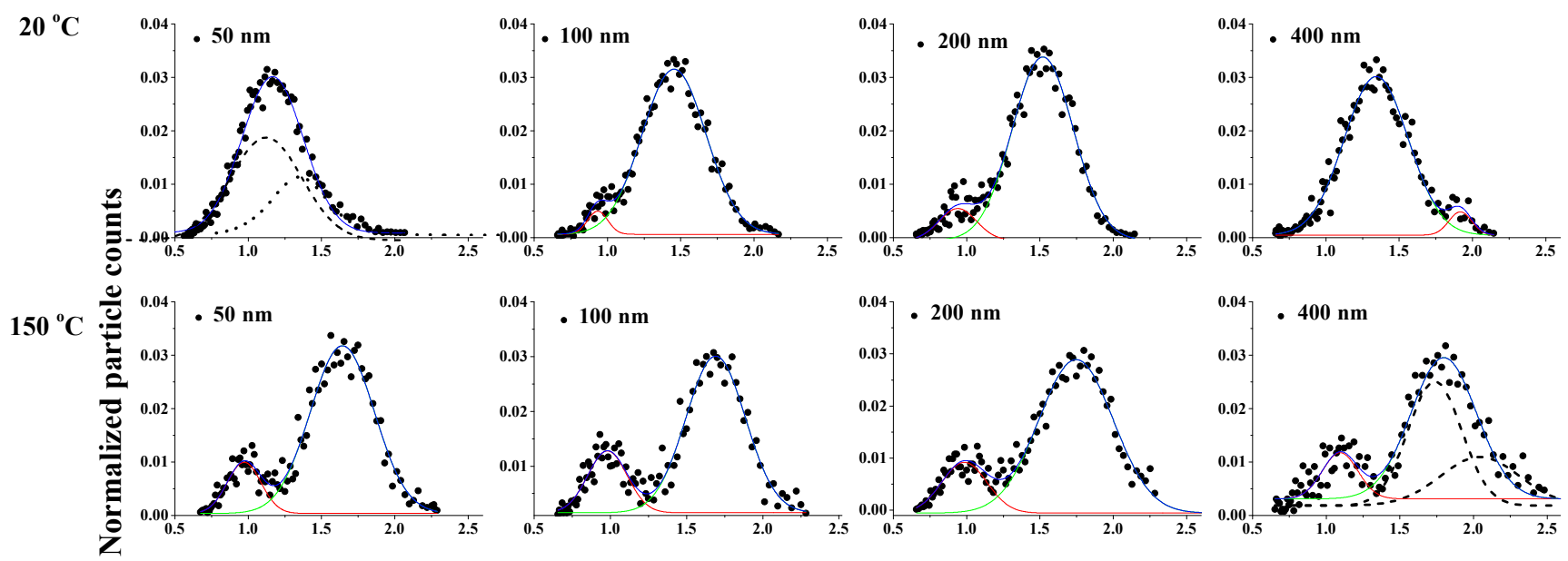

$300{ }^{\circ} \mathrm{C}$
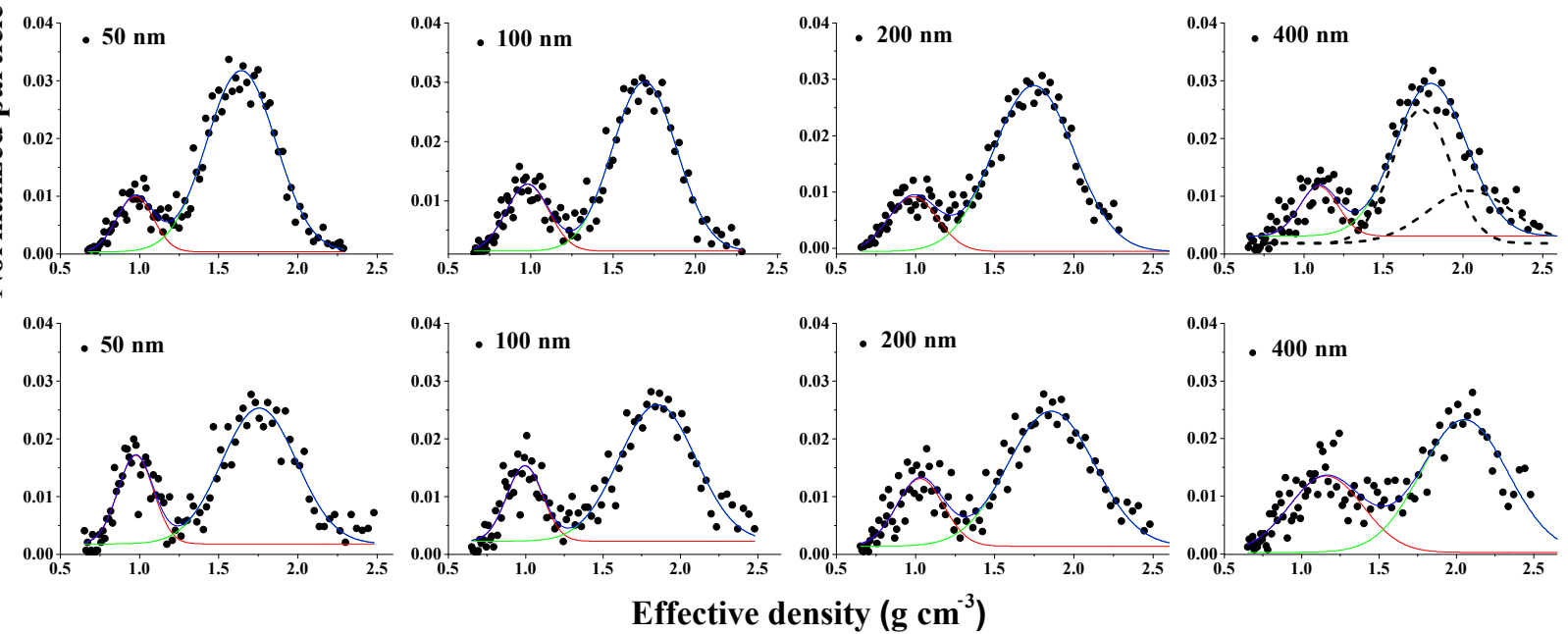

Figure 2. Average density distributions of $50,100,200$, and $400 \mathrm{~nm}$ particles selected by DMA at $20^{\circ} \mathrm{C}$ (room temperature), $150{ }^{\circ} \mathrm{C}$, and $300^{\circ} \mathrm{C}$. A Gaussian model was applied in fitting each density scan (red and green lines). The black dashes indicate the application of the Gaussian assumption models.

\subsubsection{Effective density from DMA-SPAMS measurements $\left(\rho_{\text {eff }}^{\mathrm{I}}\right)$}

The vacuum aerodynamic size distributions of 200 and $400 \mathrm{~nm}$ electrical-mobility-selected biomass burning particles are shown in Fig. 3. The dominant mode for the $200 \mathrm{~nm}$ mobility-selected particles was $280 \mathrm{~nm}$ in vacuum aerodynamic diameter with an effective density $\left(\rho_{\text {eff }}^{\mathrm{II}}\right)$ of $1.40 \mathrm{~g} \mathrm{~cm}^{-3}$ and a second mode at $360 \mathrm{~nm}\left(d_{\mathrm{va}}\right)$ with an effective density of $1.80 \mathrm{~g} \mathrm{~cm}^{-3}$. This is quite consistent with the result from the DMA-APM-CPC method. The lessintense mode at $520 \mathrm{~nm}\left(d_{\mathrm{va}}\right)$ is most likely due to doubly charged particles (Spencer et al., 2007). For $400 \mathrm{~nm}$ mobilityselected particles, the dominant mode in aerodynamic diameter was $540 \mathrm{~nm}$ with an effective density of $1.35 \mathrm{~g} \mathrm{~cm}^{-3}$. Since the less-massive modes at 660 and $840 \mathrm{~nm}$ were not in the range of doubly charged particles, these two modes were singly charged particles with effective densities of 1.65 and $2.10 \mathrm{~g} \mathrm{~cm}^{-3}$, respectively. The single-particle-level chemical composition of biomass burning particles will be discussed below.

Figure $\mathrm{S} 3$ summarizes the average effective densities $\left(\rho_{\text {eff }}^{\mathrm{I}}\right.$ and $\rho_{\text {eff }}^{\mathrm{II}}$ ) of biomass burning particles that were size selected at six different mobility diameters. Note that the density distributions of the 300 and $350 \mathrm{~nm}\left(d_{\mathrm{m}}\right)$ particles are not contained in Fig. 2 since they were similar to those of the 200 and
$400 \mathrm{~nm}\left(d_{\mathrm{m}}\right)$ particles. The $50 \mathrm{~nm}$ biomass burning particles had the lowest effective density of $1.15 \pm 0.23 \mathrm{~g} \mathrm{~cm}^{-3}$, which could be due to the aggregate structure of black carbon. Compared with $50 \mathrm{~nm}\left(d_{\mathrm{m}}\right)$ particles, the effective density of $100 \mathrm{~nm}$ particles was higher $\left(1.45 \pm 0.15 \mathrm{~g} \mathrm{~cm}^{-3}\right)$. Since the sampling limitation of SPAMS was $200 \mathrm{~nm}, \rho_{\text {eff }}^{\mathrm{II}}$ was derived only for particles in the size range of $200-400 \mathrm{~nm}\left(d_{\mathrm{m}}\right)$. Overall, these two methods had consistent results. The differences between the average values from the two methods were less than $8 \%$ for all particle sizes. We noticed that $\rho_{\mathrm{eff}}^{\mathrm{II}}$ values were generally smaller than $\rho_{\text {eff }}^{\mathrm{I}}$, which could be due to systematic error from different measurements.

\subsubsection{Thermally denuded particle effective density}

The average density distributions of $50-400 \mathrm{~nm} \quad\left(d_{\mathrm{m}}\right)$ biomass burning particles after heating at 150 and $300^{\circ} \mathrm{C}$ are shown in Fig. 2. It is worth noting that the thermally denuded particle density distribution here was not from the particles with the same original dried-particle diameter. However, our observations are still meaningful since the evolution trends of density distribution after heating were similar despite the particle size.

After heating by TD, the bimodal density distributions of biomass burning particles became more pronounced. At $150^{\circ} \mathrm{C}$, an effective density mode with a peak at 
$\sim 1.0 \mathrm{~g} \mathrm{~cm}^{-3}$ was evident for the whole size range of 50 $400 \mathrm{~nm}$ particles. The separation of the peaks after heating suggested that some less-volatile BC or soot with an effective density of $\sim 1.0 \mathrm{~g} \mathrm{~cm}^{-3}$ was possibly externally mixed with other compositions. The dominant density peak values for $50,100,200$, and $400 \mathrm{~nm}$ particles at $150^{\circ} \mathrm{C}$ were $1.64-1.80 \mathrm{~g} \mathrm{~cm}^{-3}$. Li et al. (2016) reported that the density of organic matter vaporized at $150^{\circ} \mathrm{C}$ was $0.61-0.90 \mathrm{~g} \mathrm{~cm}^{-3}$. The increase in the dominant density peak value (1.34$1.45 \mathrm{~g} \mathrm{~cm}^{-3}$ for unheated vs. $1.64-1.80 \mathrm{~g} \mathrm{~cm}^{-3}$ for $150^{\circ} \mathrm{C}$ heated) could be due to the volatilization of organics with low effective density. The dominant density peak values of $50-400 \mathrm{~nm}$ particles at $300^{\circ} \mathrm{C}$ were $1.75-2.04 \mathrm{~g} \mathrm{~cm}^{-3}$. The volatilization temperatures of ammonium nitrate and ammonium sulfate are reported to be $\sim 48-89$ and $\sim 178-205^{\circ} \mathrm{C}$, respectively (Johnson et al., 2004a, b). Thus, the fractions of ammonium nitrate and ammonium sulfate should be small at $300^{\circ} \mathrm{C}$. The increase in the dominant density peak value for 50-400 nm biomass burning particles upon heating could be due to the vaporization of volatile organics with low effective density and secondary inorganic species, such as $\mathrm{NH}_{4} \mathrm{NO}_{3}$ and $\left(\mathrm{NH}_{4}\right)_{2} \mathrm{SO}_{4}$, with densities of $\sim 1.75 \mathrm{~g} \mathrm{~cm}^{-3}$. Bond and Bergstrom (2006) reported that the density of light-absorbing carbon should be $1.7-2.1 \mathrm{~g} \mathrm{~cm}^{-3}$, which is quite high compared with the density of the volatile organics $\left(0.61-0.90 \mathrm{~g} \mathrm{~cm}^{-3}\right)$. Saleh et al. (2014) have shown that the light-absorbing organics in biomass burning particles were extremely low-volatility organic compounds. Thus, we assume that these extremely low-volatility organics play an important role in the dominant effective density mode at $300^{\circ} \mathrm{C}$.

Upon heating, the density mode of $\mathrm{KCl}$, and partly $\mathrm{K}_{2} \mathrm{SO}_{4}$, at $\sim 2.0 \mathrm{~g} \mathrm{~cm}^{-3}$ was ambiguous as the dominant mode shifted right and overlapped with the $\mathrm{KCl}$ mode (the dashed lines shown in Fig. 2). However, at $300^{\circ} \mathrm{C}$, the dominant mode of $400 \mathrm{~nm}$ particles was at $2.05 \mathrm{~g} \mathrm{~cm}^{-3}$, which fit the density of potassium salts, indicating that the main material of $400 \mathrm{~nm}$ heated $(\sim 800 \mathrm{~nm}$ unheated; detected by a tandem DMAs) biomass burning particles is potassium salts with vaporization temperatures above $700^{\circ} \mathrm{C}$ (Knudsen et al., 2004).

With heating by TD, the aerodynamic size distributions of 200 and $400 \mathrm{~nm}$ electrical-mobility-selected biomass burning particles at $300^{\circ} \mathrm{C}$ are shown in Fig. 3. The increase in $\rho_{\text {eff }}^{\mathrm{II}}$ upon heating was consistent with that of $\rho_{\mathrm{eff}}^{\mathrm{I}}$.

\subsubsection{Shape factor}

The shape of particles has been suggested to play an important role in their optical properties (Zhang et al., 2008) and mixing state (China et al., 2013). Shape factor was introduced to account for the ratio of the drag forces on a particle due to nonspherical or irregular shape. Shape factor, which can be extracted based on the measurement of particle density and mass, has been introduced in Sect. 2.3.1.

We calculated the ratio of the estimated $m_{\mathrm{p}}$ to the exact $m_{\mathrm{p}}$ as a function of $d_{\mathrm{m}}$ and $\chi$ (shown in Fig. S4). For nonspher- ical particles $(\chi>1)$, the estimated mass was larger than the actual mass. We calculated the estimated mass using the exact $\rho_{\text {eff }}^{\text {II }}$ measured by the DMA-SPAMS to replace the $\rho_{\text {eff }}^{\mathrm{I}}$ in Eq. (2). The ratios of the estimated mass to the exact mass for 200, 300, 350, and $400 \mathrm{~nm}$ mobility-selected particles were 1.4, 1.3, 1.3, and 1.2, respectively (red dots in Fig. S4). Thus, we could estimate the $\chi$ of the particles measured using the DMA-SPAMS in the size range of $200-400 \mathrm{~nm}$. Overall, the $\chi$ of $200-400 \mathrm{~nm}$ biomass burning particles in this work exceeded $1.2(\sim 1.2-2.2)$. The $\chi$ decreased with the increase in $d_{\mathrm{m}}$, while the effective density showed the same trend. The more regular shape and lower effective density of $400 \mathrm{~nm}$ particles compared with that of $200 \mathrm{~nm}$ particles could be due to the particle chemical composition and particle voids (discussed in Sect. 3.2).

\subsection{Size-resolved chemical composition}

The mass spectra of individual biomass burning particles have been studied in previous work (Silva et al., 1999; Zauscher et al., 2013). Based on the mass spectra of single particles, the biomass burning particles were classified into six particle types: (1) BB-CN: biomass burning (BB) particles with a strong $\mathrm{CN}^{-}\left(m / z-26\left[\mathrm{CN}^{-}\right]\right)$peak; (2) BB-EC: BB particles with strong elemental carbon clusters $\left(\mathrm{C}_{n}^{+/-}\right)$; (3) BB-nitrate: $\mathrm{BB}$ particles with strong nitrate $\left(m / z-46\left[\mathrm{NO}_{2}^{-}\right],-62\left[\mathrm{NO}_{3}^{-}\right]\right)$signals; (4) BB-sulfate: $\mathrm{BB}$ particles with strong sulfate $\left(\mathrm{m} / z-97\left[\mathrm{HSO}_{4}^{-}\right]\right)$signals; (5) BB-KCl: $\mathrm{BB}$ particles with strong potassium chlorine $\left(m / z 113\left[\mathrm{~K}_{2} \mathrm{Cl}^{+}\right]\right)$signals; and (6) BB-OC: BB particles with strong organic carbon peaks (e.g., $m / z 27\left[\mathrm{C}_{2} \mathrm{H}_{3}^{+}\right]$, $\left.37\left[\mathrm{C}_{3} \mathrm{H}^{+}\right], 43\left[\mathrm{C}_{3} \mathrm{H}_{7}^{+}\right], 51\left[\mathrm{C}_{4} \mathrm{H}_{3}^{+}\right]\right)$. The naming of the chemical classes is based on some of the dominant chemical species in an attempt to keep the names short. The mass spectra for each particle type are presented in Fig. S5. The percentages of the six particle types in different modes of aerodynamic size distribution for 200 and $400 \mathrm{~nm}$ mobilityselected particles are shown in Fig. 3. For $200 \mathrm{~nm}$ mobilityselected particles, the dominant particle types were BB-EC and BB-CN. The percentages of particle types within the two aerodynamic modes differ slightly. Compared with the first mode, the second mode contains more BB-CN $(24.4 \%$ vs. $29.6 \%)$, more $\mathrm{BB}-\mathrm{KCl}(1.0 \%$ vs. $4.3 \%)$, and less BBEC (32.2\% vs. $22.9 \%)$. We supposed that the density of each particle type largely depended on the dominant species. The exact effective density of each particle type could not be obtained directly, while the relative value compared with other particle types could be inferred from the material density of the dominant species. For example, the BB-KCl type might have a higher effective density compared with others since the dominant composition $\mathrm{KCl}$ has a material density of $\sim 1.99 \mathrm{~g} \mathrm{~cm}^{-3}$ (Lide, 2008). The increased BB-KCl and the decrease in BB-EC $\left(\sim 1.0 \mathrm{~g} \mathrm{~cm}^{-3}\right)$ resulted in a higher effective density in the second mode than the first mode. 


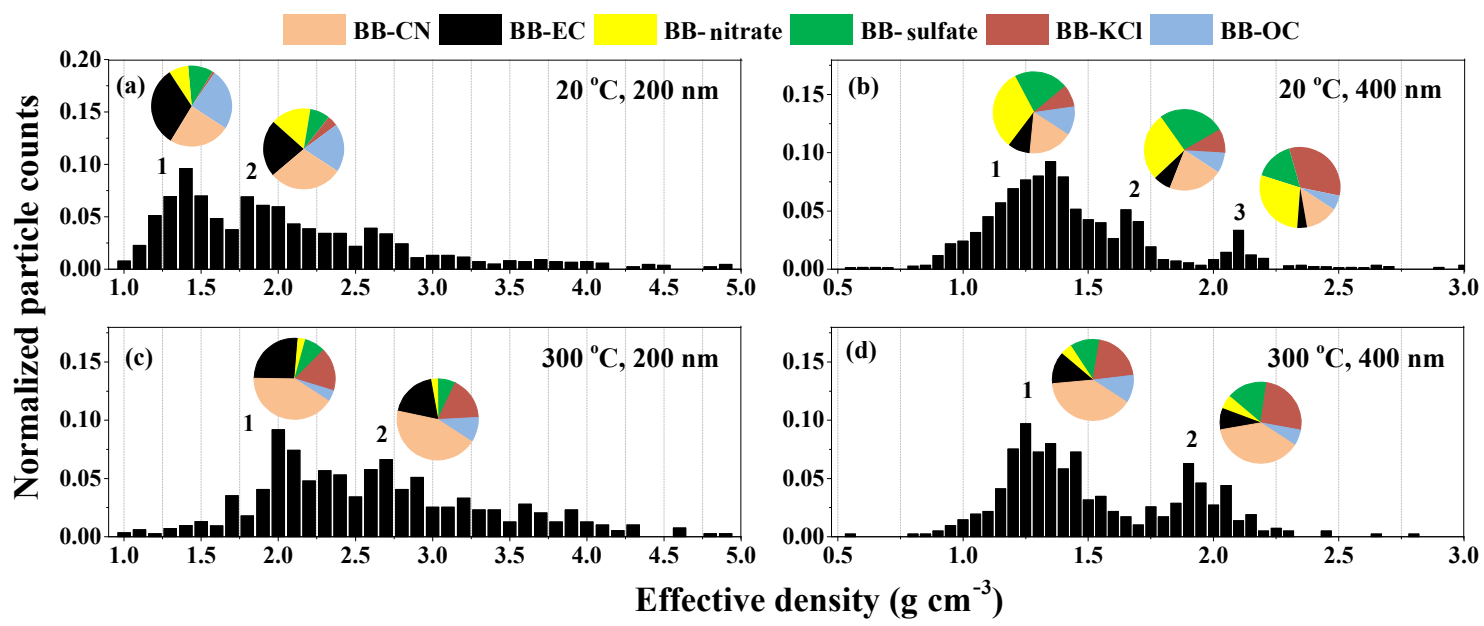

Figure 3. Vacuum aerodynamic size distributions detected by the SPAMS of 200 and $400 \mathrm{~nm}$ electrical-mobility-selected biomass burning particles, and pie charts for the particle types in different aerodynamic modes at $20^{\circ} \mathrm{C}$ (room temperature) and $300^{\circ} \mathrm{C}$.

The fractional distributions of the six particle types for 200 and $400 \mathrm{~nm}$ mobility-selected particles were apparently different (Fig. 3). For $400 \mathrm{~nm}$ mobility-selected particles, the proportions of $\mathrm{BB}$-nitrate, $\mathrm{BB}$-sulfate, and $\mathrm{BB}-\mathrm{KCl}$ types were larger than those of $200 \mathrm{~nm}$ mobility-selected particles. The dominant chemical species for BB-nitrate and BBsulfate particle types could be $\mathrm{NH}_{4} \mathrm{NO}_{3}$ and $\left(\mathrm{NH}_{4}\right)_{2} \mathrm{SO}_{4}$ with a material density of $\sim 1.75 \mathrm{~g} \mathrm{~cm}^{-3}$ (Lide, 2008). Compared with other types, BB-nitrate, $\mathrm{BB}$-sulfate, and $\mathrm{BB}-\mathrm{KCl}$ were the particle types with a higher density. However, the effective density for $400 \mathrm{~nm}$ mobility-selected particles was lower than that of $200 \mathrm{~nm}$. In addition to the compositional differences, particle morphology could be another reason for the observed differences in the effective densities between these two sizes. Indeed, it has been found that the morphology, including void ratio, particle shape factor, and the fractal dimension of particles, all greatly affect particle effective density (DeCarlo et al., 2004). Though the shape factor discussed in Sect. 3.1 had shown that the $400 \mathrm{~nm}\left(d_{\mathrm{m}}\right)$ particles had a more spherical morphology, their lower average effective density compared to smaller particles could be due to the voids in particles. Amorphous species such as $\mathrm{NH}_{4} \mathrm{NO}_{3}$ (Audebrand et al., 1997) could also lead to the low effective density of particles. Thus, we supposed that the lower effective density of $400 \mathrm{~nm}$ particles compared with $200 \mathrm{~nm}$ particles was caused by the large proportion of $\mathrm{NH}_{4} \mathrm{NO}_{3}$ and $\left(\mathrm{NH}_{4}\right)_{2} \mathrm{SO}_{4}$ with fluffy material properties.

For $400 \mathrm{~nm}$ mobility-selected particles, the pie charts of particle type were almost identical for the first and second modes (as shown in Fig. $3 \mathrm{~b} ; 20^{\circ} \mathrm{C}$ ). Thus, we assume that these two modes were derived from one effective density mode. The proportion of $\mathrm{BB}-\mathrm{KCl}$ in the third mode at $840 \mathrm{~nm}$ with an effective density of $2.10 \mathrm{~g} \mathrm{~cm}^{-3}$ greatly increased compared with the first two modes (8.8\%, $9.2 \%$ vs. $32.7 \%)$. The increased $\mathrm{BB}-\mathrm{KCl}$ indicated that the $\mathrm{KCl}$ crystals were externally mixed and tended to be mixed with larger-size particles; this was consistent with the DMA-APM-CPC result.

Upon heating by $\mathrm{TD}$, the proportions of $\mathrm{BB}-\mathrm{CN}$ and $\mathrm{BB}-$ $\mathrm{KCl}$ increased, indicating that these types of particles were composed of less-volatile species (shown in Fig. 3; Zhai et al., 2015). At $300^{\circ} \mathrm{C}$, the fractions of BB-nitrate and BBsulfate decreased, which is consistent with the volatilization temperature ranges of ammonium nitrate $\left(\sim 48-89^{\circ} \mathrm{C}\right)$ and ammonium sulfate $\left(\sim 178-205^{\circ} \mathrm{C}\right.$; Johnson et al., 2004a, b). The high effective density $(>2.0)$ of biomass burning particles at $300^{\circ} \mathrm{C}$ could be due to the vaporization of volatile organics with low density since the BB-OC type decreased drastically after thermal treatment. The increasing proportion of $\mathrm{BB}-\mathrm{KCl}$ upon heating could be another important reason for the higher effective density at $300^{\circ} \mathrm{C}$.

\subsection{Size-resolved optical properties}

\subsubsection{Single-scattering albedo (SSA)}

The single-scattering albedo (SSA) was calculated using the following equation:

$\operatorname{SSA}(\lambda)=b_{\text {scat }}(\lambda) /\left[b_{\text {abs }}(\lambda)+b_{\text {sca }}(\lambda)\right]$,

where $b_{\text {scat }}$ is the particle light-scattering coefficient, $b_{\text {abs }}$ is the light absorption coefficient, and $\lambda$ is wavelength. The light-scattering and extinction coefficients $\left(b_{\text {ext }},=b_{\text {abs }}+\right.$ $b_{\text {sca }}$ ) for biomass burning particles in this work were measured at 530 and $450 \mathrm{~nm}$ wavelengths using CAPSs.

The size-resolved SSAs for biomass burning particles are shown in Fig. 4. Overall, the SSAs for biomass burning particles in the mobility size range of 50-400 nm varied narrowly. It is worth noting that the optical measurement was based on bulk measurement by CAPSs, which is not sensitive to the diversity of particle mixing states. 

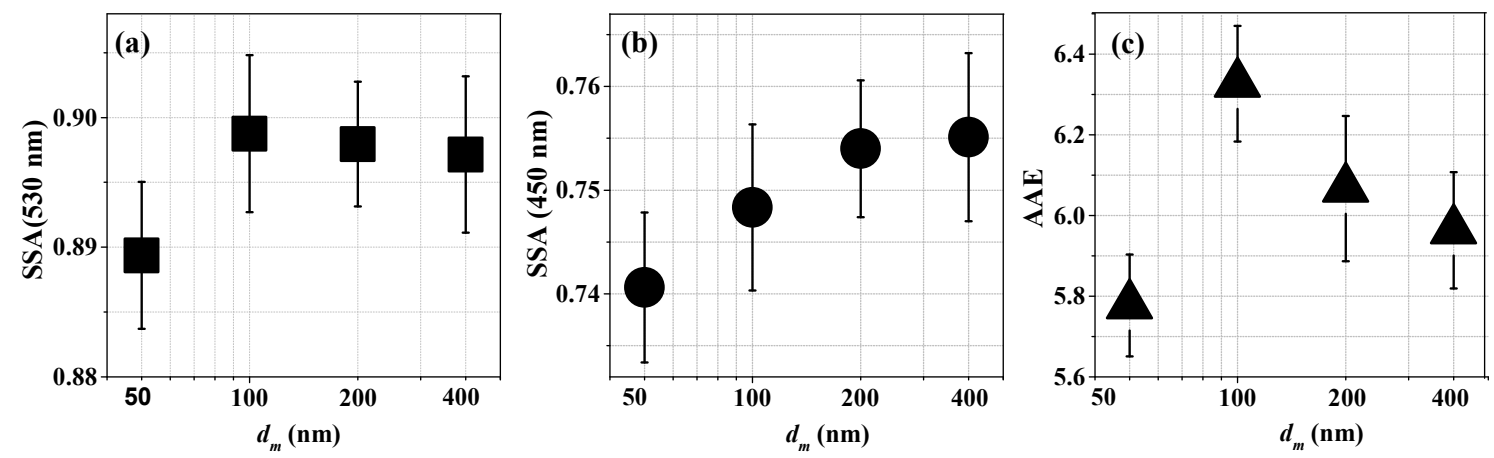

Figure 4. (a-b) Size-resolved single-scattering albedo (SSA) at wavelengths of 530 and $450 \mathrm{~nm}$. (c) Ångström absorption exponent (AAE) of biomass burning particles at room temperature $\left(20^{\circ} \mathrm{C}\right)$.

The SSA $(530 \mathrm{~nm})$ for $50 \mathrm{~nm}$ particles was the lowest $(0.889 \pm 0.006)$ as the percentage of strong light-absorbing black carbon for particles in this size range was larger (shown in Fig. 3; discussed in Sect. 3.2). For 100-400 nm biomass burning particles, the SSAs were relatively steady $(0.897 \pm 0.006-0.900 \pm 0.006)$.

The size-resolved SSAs at $450 \mathrm{~nm}(\lambda)$ for biomass burning particles were generally lower than those at $530 \mathrm{~nm}(\lambda)$. Previous studies have shown that biomass burning was an important source of brown carbon $(\mathrm{BrC})$, which is light absorbing in the UV-visible range (Lack and Cappa, 2010). For $50 \mathrm{~nm}\left(d_{\mathrm{m}}\right)$ particles, the SSA $(\lambda=450 \mathrm{~nm})$ was also the lowest due to the dominance of the strong light-absorbing BC in these particles. However, unlike the trend of size-resolved SSAs $(\lambda=530 \mathrm{~nm})$, the SSA $(\lambda=450 \mathrm{~nm})$ of $100-400 \mathrm{~nm}$ particles increased as the size increased. It has been shown that brown carbon arising from biomass burning is primarily composed of extremely low-volatility organic compounds (Saleh et al., 2014). The $\mathrm{CN}^{-}$in biomass burning particles is representative of some extremely low-volatility nitrogencontaining organics (Zhai et al., 2015). As shown in Fig. 3, compared with $400 \mathrm{~nm}$ particles, the proportion of organic matter (BB-CN, BB-OC) was larger for $200 \mathrm{~nm}$ particles. The nitrogen-containing species might indicate the existence of light-absorbing organics. The lower SSA $(\lambda=450 \mathrm{~nm})$ for $200 \mathrm{~nm}$ particles might indicate a larger proportion of $\mathrm{BrC}$. We assumed that the lower SSA $(\lambda=450 \mathrm{~nm})$ for $100 \mathrm{~nm}$ performed in a similar way with a larger proportion of $\mathrm{BrC}$.

\subsection{2 Ångström absorption exponent (AAE)}

To investigate the wavelength dependence of the absorption coefficients, we determined the Ångström absorption exponent (AAE) based on absorption measurements at two different wavelengths $\left(\lambda_{1}\right.$ and $\left.\lambda_{2}\right)$ using the following equation:

$\operatorname{AAE}\left(\lambda_{1} / \lambda_{2}\right)=-\ln \left[b_{\mathrm{abs}}\left(\lambda_{1}\right) / b_{\mathrm{abs}}\left(\lambda_{2}\right)\right] / \ln \left(\lambda_{1} / \lambda_{2}\right)$.

The AAE in this work was calculated from the light absorption coefficients at wavelengths of 450 and $530 \mathrm{~nm}$ mea- sured by the CAPSs. The uncertainties in the calculated AAE values can be caused by the uncertainties in the calibration factors of the CAPSs. The size-resolved AAEs for biomass burning particles are shown in Fig. 4. Black carbon is highly absorbing in the visible spectrum with little variation with wavelength and shows an AAE of $\sim 1.0$ (Bergstrom et al., 2002). As brown carbon species absorb light in the UV-visible range, $\mathrm{BrC}$-containing particles usually exhibit an AAE above 1 (Martinsson et al., 2015). Lack and Cappa (2010) used modeling to calculate AAE values and suggested that particles with AAEs exceeding 1.6 should be classified as BrC. In our study, the AAE values of particles in the size range of $50-400 \mathrm{~nm}$ were higher than 1.6 , indicating that they were $\mathrm{BrC}$-containing particles from biomass burning. Among all sizes, the AAE of $50 \mathrm{~nm}$ biomass burning particles was the lowest $(\sim 5.8)$, while that of $100 \mathrm{~nm}$ particles was the highest $(\sim 6.3)$. The main light-absorbing functional group in the UV-visible range is the conjugated double bond (Laskin et al., 2015). BB-CN and BB-OC particle types identified by mass spectra in our work tended to contain more large molecules of $\mathrm{BrC}$ with light-absorbing functional groups. We noticed that the proportion of BB-OC species was larger in $200 \mathrm{~nm}$ particles (Fig. 3) with higher AAE values compared to $400 \mathrm{~nm}$ particles. Thus, we suppose that the highest AAE value observed for $100 \mathrm{~nm}$ particles might be the result of the largest $\mathrm{BrC}$ proportion.

The SSA and AAE values of total biomass burning particles are shown in Table S2. The decrease in SSA values upon heating was due to the vaporization of secondary inorganic species like $\mathrm{NH}_{4} \mathrm{NO}_{3}$ and less-absorbing organics. The AAE values for all particles at 150 and $300^{\circ} \mathrm{C}$ were $\sim 19$ and $\sim 64 \%$, lower than those at room temperature $\left(20^{\circ} \mathrm{C}\right)$. The significant decrease in AAE at $300^{\circ} \mathrm{C}$ could be due to the vaporization of light-absorbing organics in the temperature range of $150-300^{\circ} \mathrm{C}$. However, the AAE value at $300^{\circ} \mathrm{C}$ was still above 1.6, indicating the presence of extremely low-volatility light-absorbing organics in biomass burning particles. McMeeking et al. (2014) found that the strongly light-absorbing biomass burning particles tended to have a 
weak wavelength-dependent absorption, while the weakly light-absorbing particles tended to have a strong wavelengthdependent absorption, which is consistent with our results. In this work, the high values of AAE $(\sim 6.23)$ and $\operatorname{SSA}(\sim 0.89$, at $530 \mathrm{~nm}$ ) suggested that the light absorbtion of rice straw burning particles was relatively weak compared to the particles emitted from other types of biofuels.

\section{Conclusions}

As a major primary source of aerosols, biomass burning emissions significantly impact the global radiative budget. It is important to understand the physical and chemical properties of biomass burning particles as well as their links to optical properties. In this work, rice straw was combusted as a representative material for biomass burning in southern China. A series of comprehensive methods was used to detect the size-resolved chemical composition, effective density, and optical properties of the particles emitted from the burns.

Two methods were utilized to measure the effective density of the biomass burning particles. The DMA-APM-CPC system, which has been widely used in chamber and field work, offered size-resolved information on the particle effective density. The DMA-SPAMS system provided information on the physical property and chemical composition at the single-particle level. The $50 \mathrm{~nm}\left(d_{\mathrm{m}}\right)$ biomass burning particles had the lowest effective density of $1.15 \pm 0.23 \mathrm{~g} \mathrm{~cm}^{-3}$, which was due to the large proportion of fractal black carbon. The apparent single-peak density distribution of $50 \mathrm{~nm}$ particles was due to the combination of two modes (BC and organic matter). The independent modes at $0.9-1.1 \mathrm{~g} \mathrm{~cm}^{-3}$ shown in the density distribution of 100 and $200 \mathrm{~nm}$ particles and at $\sim 1.92 \mathrm{~g} \mathrm{~cm}^{-3}$ shown in $400 \mathrm{~nm}$ particles indicated that $\mathrm{BC}$ and crystalline species, such as $\mathrm{KCl}$, in fresh biomass burning particles tended to be externally mixed with organic carbon. With heating by TD, the separation of the effective density distribution modes confirmed the presence of $\mathrm{BC}$, potassium salts, and less-volatile $\mathrm{OC}$ in the biomass burning particles.

The effective density measured by the DMA-SPAMS system was consistent with the result from the DMA-APMCPC method. The dominant modes in the effective density distributions of 200 and $400 \mathrm{~nm}$ mobility-selected particles were 1.40 and $1.35 \mathrm{~g} \mathrm{~cm}^{-3}$, respectively. The crystalline $\mathrm{KCl}$ with an effective density of $2.10 \mathrm{~g} \mathrm{~cm}^{-3}$ (with BB-KCl accounting for $32.7 \%$ ) was observed in the density distribution for $400 \mathrm{~nm}$ particles measured by DMA-SPAMS. The proportions of $\mathrm{BB}$-nitrate, $\mathrm{BB}$-sulfate, and $\mathrm{BB}-\mathrm{KCl}$ types in $400 \mathrm{~nm}$ mobility-selected particles were larger than those in $200 \mathrm{~nm}$ mobility-selected particles. Compared with $200 \mathrm{~nm}$ particles, $400 \mathrm{~nm}$ particles showed more spherical morphology but a lower effective density, which could be due to the larger proportion of low-density organics and amorphous $\mathrm{NH}_{4} \mathrm{NO}_{3}$.

The size-resolved extinction and scattering coefficients were measured by CAPSs at wavelengths of 450 and $530 \mathrm{~nm}$. The SSA $(\lambda=530 \mathrm{~nm})$ for $50 \mathrm{~nm}$ particles was the lowest $(0.889 \pm 0.006)$ because of the presence of a larger percentage of the strongly light-absorbing black carbon particles in this size mode. The size-resolved SSAs $(\lambda=450 \mathrm{~nm})$ for biomass burning particles were generally lower than the SSAs $(\lambda=530 \mathrm{~nm})$. The AAE values for the size range of $50-400 \mathrm{~nm}$ particles were all above 1.6, indicating the significant presence of brown carbon in all sizes. The AAE value was the lowest for $50 \mathrm{~nm}$ particles $(\sim 5.8)$, while it was the highest for $100 \mathrm{~nm}$ particles $(\sim 6.3)$. Compared with $400 \mathrm{~nm}$ particles, the proportions of BB-OC and BB-CN were larger for $200 \mathrm{~nm}$ particles; this might indicate a higher possibility of the existence of light-absorbing organics. Our work emphasizes the complex mixing states of aerosols from primary sources. Further research on how particle morphology affects the optical properties of biomass burning particles is needed.

Data availability. The data presented in this article are available from the authors upon request (yangxin@fudan.edu.cn).

\section{The Supplement related to this article is available online at https://doi.org/10.5194/acp-17-7481-2017-supplement.}

Competing interests. The authors declare that they have no conflict of interest.

Acknowledgements. This work was supported by the National Natural Science Foundation of China (91544224, 21507010), the Ministry of Science \& Technology of China (2012YQ220113-4), the Science \& Technology Commission of Shanghai Municipality (14DZ1202900), and the Changjiang Scholars program of the Chinese Ministry of Education.

Edited by: Ryan Sullivan

Reviewed by: three anonymous referees

\section{References}

Adachi, K. and Buseck, P. R.: Atmospheric tar balls from biomass burning in Mexico, J. Geophys. Res.-Atmos., 116, D05204, https://doi.org/10.1029/2010jd015102, 2011.

Allen, M. D. and Raabe, O. G.: Slip correction measurements of spheical solid aerosol-particles in an improved millikan apparatus, Aerosol Sci. Technol., 4, 269-286, https://doi.org/10.1080/02786828508959055, 1985.

Andreae, M. O. and Merlet, P.: Emission of trace gases and aerosols from biomass burning, Global Biogeochem. Cy., 15, 955-966, https://doi.org/10.1029/2000gb001382, 2001. 
Audebrand, N., Auffredic, J. P., and Louer, D.: Thermal decomposition of cerous ammonium nitrate tetrahydrate studied with temperature-dependent X-ray powder diffraction and thermal analysis, Thermochim. Acta, 293, 65-76, https://doi.org/10.1016/s0040-6031(97)00064-6, 1997.

Barone, T. L., Lall, A. A., Storey, J. M. E., Mulholland, G. W., Prikhodko, V. Y., Frankland, J. H., Parks, J. E., and Zachariah, M. R.: Size-resolved density measurements of particle emissions from an advanced combustion diesel engine: effect of aggregate morphology, Energ. Fuel., 25, 1978-1988, https://doi.org/10.1021/ef200084k, 2011.

Bergstrom, R. W., Russell, P. B., and Hignett, P.: Wavelength dependence of the absorption of black carbon particles: Predictions and results from the TARFOX experiment and implications for the aerosol single scattering albedo, J. Atmos. Sci., 59, 567-577, https://doi.org/10.1175/15200469(2002)059<0567:wdotao>2.0.co;2, 2002.

Bi, X. H., Zhang, G. H., Li, L., Wang, X. M., Li, M., Sheng, G. Y., Fu, J. M., and Zhou, Z.: Mixing state of biomass burning particles by single particle aerosol mass spectrometer in the urban area of PRD, China, Atmos. Environ., 45, 3447-3453, https://doi.org/10.1016/j.atmosenv.2011.03.034, 2011.

Bond, T. C., Streets, D. G., Yarber, K. F., Nelson, S. M., Woo, J.-H., and Klimont, Z.: A technology-based global inventory of black and organic carbon emissions from combustion, J. Geophys. Res.-Atmos., 109, D14203, https://doi.org/10.1029/2003jd003697, 2004.

Bond, T. C. and Bergstrom, R. W.: Light absorption by carbonaceous particles: An investigative review, Aerosol Sci. Technol., 40, 27-67, https://doi.org/10.1080/02786820500421521, 2006.

Bond, T. C., Doherty, S. J., Fahey, D. W., Forster, P. M., Berntsen, T., DeAngelo, B. J., Flanner, M. G., Ghan, S., Karcher, B., Koch, D., Kinne, S., Kondo, Y., Quinn, P. K., Sarofim, M. C., Schultz, M. G., Schulz, M., Venkataraman, C., Zhang, H., Zhang, S., Bellouin, N., Guttikunda, S. K., Hopke, P. K., Jacobson, M. Z., Kaiser, J. W., Klimont, Z., Lohmann, U., Schwarz, J. P., Shindell, D., Storelvmo, T., Warren, S. G., and Zender, C. S.: Bounding the role of black carbon in the climate system: A scientific assessment, J. Geophys. Res.-Atmos., 118, 5380-5552, https://doi.org/10.1002/jgrd.50171, 2013.

Cao, G., Zhang, X., Wang, Y., and Zheng, F.: Estimation of emissions from field burning of crop straw in China, Chinese Sci. Bull., 53, 784-790, https://doi.org/10.1007/s11434-008-0145-4, 2008.

Chan, T. W., Brook, J. R., Smallwood, G. J., and Lu, G.: Time-resolved measurements of black carbon light absorption enhancement in urban and near-urban locations of southern Ontario, Canada, Atmos. Chem. Phys., 11, 10407-10432, https://doi.org/10.5194/acp-11-10407-2011, 2011.

Chand, D., Wood, R., Anderson, T. L., Satheesh, S. K., and Charlson, R. J.: Satellite-derived direct radiative effect of aerosols dependent on cloud cover, Nat. Geosci., 2, 181-184, https://doi.org/10.1038/ngeo437, 2009.

China, S., Mazzoleni, C., Gorkowski, K., Aiken, A. C., and Dubey, M. K.: Morphology and mixing state of individual freshly emitted wildfire carbonaceous particles, Nat. Commun., 4, 2122, https://doi.org/10.1038/ncomms3122, 2013.
DeCarlo, P. F., Slowik, J. G., Worsnop, D. R., Davidovits, P., and Jimenez, J. L.: Particle morphology and density characterization by combined mobility and aerodynamic diameter measurements. Part 1: theory, Aerosol Sci. Technol., 38, 1185-1205, https://doi.org/10.1080/027868290903907, 2004.

Giordano, M., Espinoza, C., and Asa-Awuku, A.: Experimentally measured morphology of biomass burning aerosol and its impacts on CCN ability, Atmos. Chem. Phys., 15, 1807-1821, https://doi.org/10.5194/acp-15-1807-2015, 2015.

Hand, J. L., Day, D. E., McMeeking, G. M., Levin, E. J. T., Carrico, C. M., Kreidenweis, S. M., Malm, W. C., Laskin, A., and Desyaterik, Y.: Measured and modeled humidification factors of fresh smoke particles from biomass burning: role of inorganic constituents, Atmos. Chem. Phys., 10, 6179-6194, https://doi.org/10.5194/acp-10-6179-2010, 2010.

Hinds, W. C.: Aerosol Technology: Properties, behavior, and measurement of airborne particles, Wiley, 1999.

Hoffer, A., Gelencsér, A., Guyon, P., Kiss, G., Schmid, O., Frank, G. P., Artaxo, P., and Andreae, M. O.: Optical properties of humiclike substances (HULIS) in biomass-burning aerosols, Atmos Chem. Phys., 6, 3563-3570, https://doi.org/10.5194/acp-6-35632006, 2006.

Hopkins, R. J., Lewis, K., Desyaterik, Y., Wang, Z., Tivanski, A. V., Arnott, W. P., Laskin, A., and Gilles, M. K.: Correlations between optical, chemical and physical properties of biomass burn aerosols, Geophys. Res. Lett., 34, L18806, https://doi.org/10.1029/2007g1030502, 2007.

Hu, M., Peng, J., Sun, K., Yue, D., Guo, S., Wiedensohler, A., and $\mathrm{Wu}, \mathrm{Z}$. : Estimation of size-resolved ambient particle density based on the measurement of aerosol number, mass, and chemical size distributions in the winter in Beijing, Environ. Sci. Technol., 46, 9941-9947, https://doi.org/10.1021/es204073t, 2012.

Huang, Y., Li, L., Li, J., Wang, X., Chen, H., Chen, J., Yang, X., Gross, D., Wang, H., and Qiao, L.: A case study of the highly time-resolved evolution of aerosol chemical and optical properties in urban Shanghai, China, Atmos. Chem. Phys., 13, 39313944, https://doi.org/10.5194/acp-13-3931-2013, 2013.

Huo, J., Lu, X., Wang, X., Chen, H., Ye, X., Gao, S., Gross, D. S., Chen, J., and Yang, X.: Online single particle analysis of chemical composition and mixing state of crop straw burning particles: from laboratory study to field measurement, Front. Env. Sci. Eng., 10, 244-252, https://doi.org/10.1007/s11783-015-0768-z, 2016.

Jacobson, M. Z.: Isolating nitrated and aromatic aerosols and nitrated aromatic gases as sources of ultraviolet light absorption, J. Geophys. Res.-Atmos., 104, 3527-3542, https://doi.org/10.1029/1998jd100054, 1999.

Johnson, G., Ristovski, Z., and Morawska, L.: Application of the VH-TDMA technique to coastal ambient aerosols, Geophys. Res. Lett., 31, L16105, https://doi.org/10.1029/2004g1020126, 2004a.

Johnson, G. R., Ristovski, Z., and Morawska, L.: Method for measuring the hygroscopic behaviour of lower volatility fractions in an internally mixed aerosol, J. Aerosol Sci., 35, 443-455, https://doi.org/10.1016/j.jaerosci.2003.10.008, 2004b.

Katrib, Y., Martin, S. T., Rudich, Y., Davidovits, P., Jayne, J. T., and Worsnop, D. R.: Density changes of aerosol particles as a result of chemical reaction, Atmos. Chem. Phys., 5, 275-291, https://doi.org/10.5194/acp-5-275-2005, 2005. 
Kelly, W. P. and McMurry, P. H.: Measurement of particle density by inertial classification of differential mobility analyzergenerated monodisperse aerosols, Aerosol Sci. Technol., 17, 199-212, https://doi.org/10.1080/02786829208959571, 1992.

Knudsen, J. N., Jensen, P. A., and Dam-Johansen, K.: Transformation and release to the gas phase of $\mathrm{Cl}, \mathrm{K}$, and $\mathrm{S}$ during combustion of annual biomass, Energ. Fuel., 18, 1385-1399, https://doi.org/10.1021/ef049944q, 2004.

Lack, D. A. and Cappa, C. D.: Impact of brown and clear carbon on light absorption enhancement, single scatter albedo and absorption wavelength dependence of black carbon, Atmos. Chem. Phys., 10, 4207-4220, https://doi.org/10.5194/acp10-4207-2010, 2010.

Lack, D. A., Langridge, J. M., Bahreini, R., Cappa, C. D., Middlebrook, A. M., and Schwarz, J. P.: Brown carbon and internal mixing in biomass burning particles, P. Natl. Acad. Sci. USA, 109, 14802-14807, https://doi.org/10.1073/pnas.1206575109, 2012.

Laskin, A., Laskin, J., and Nizkorodov, S. A.: Chemistry of atmospheric brown carbon, Chem. Rev., 115, 4335-4382, https://doi.org/10.1021/cr5006167, 2015.

Lee, A. K. Y., Willis, M. D., Healy, R. M., Wang, J. M., Jeong, C.-H., Wenger, J. C., Evans, G. J., and Abbatt, J. P. D.: Singleparticle characterization of biomass burning organic aerosol (BBOA): evidence for non-uniform mixing of high molecular weight organics and potassium, Atmos. Chem. Phys., 16, 55615572, https://doi.org/10.5194/acp-16-5561-2016, 2016.

Leskinen, A. P., Jokiniemi, J. K., and Lehtinen, K. E. J.: Characterization of aging wood chip combustion aerosol in an environmental chamber, Atmos. Environ., 41, 3713-3721, https://doi.org/10.1016/j.atmosenv.2006.12.016, 2007.

Li, C., Ma, Z., Chen, J., Wang, X., Ye, X., Wang, L., Yang, X., Kan, H., Donaldson, D. J., and Mellouki, A.: Evolution of biomass burning smoke particles in the dark, Atmos. Environ., 120, 244252, https://doi.org/10.1016/j.atmosenv.2015.09.003, 2015.

Li, C., Hu, Y., Chen, J., Ma, Z., Ye, X., Yang, X., Wang, L., Wang, X., and Mellouki, A.: Physiochemical properties of carbonaceous aerosol from agricultural residue burning: Density, volatility, and hygroscopicity, Atmos. Environ., 140, 94-105, https://doi.org/10.1016/j.atmosenv.2016.05.052, 2016.

Li, L., Huang, Z., Dong, J., Li, M., Gao, W., Nian, H., Fu, Z., Zhang, G., Bi, X., Cheng, P., and Zhou, Z.: Real time bipolar time-of-flight mass spectrometer for analyzing single aerosol particles, Int. J. Mass Spectrom., 303, 118-124, https://doi.org/10.1016/j.ijms.2011.01.017, 2011.

Lide, D. R.: CRC handbook of chemistry and physics, CRC, Taylor and Francis, 2008.

Martins, J. V., Hobbs, P. V., Weiss, R. E., and Artaxo, P.: Sphericity and morphology of smoke particles from biomass burning in Brazil, J. Geophys. Res.-Atmos., 103, 32051-32057, https://doi.org/10.1029/98jd01153, 1998.

Martinsson, J., Eriksson, A. C., Nielsen, I. E., Malmborg, V. B., Ahlberg, E., Andersen, C., Lindgren, R., Nystrom, R., Nordin, E. Z., Brune, W. H., Svenningsson, B., Swietlicki, E., Boman, C., and Pagels, J. H.: Impacts of combustion conditions and photochemical processing on the light absorption of biomass combustion aerosol, Environ. Sci. Technol., 49, 14663-14671, https://doi.org/10.1021/acs.est.5b03205, 2015.
McMeeking, G. R., Fortner, E., Onasch, T. B., Taylor, J. W., Flynn, M., Coe, H., and Kreidenweis, S. M.: Impacts of nonrefractory material on light absorption by aerosols emitted from biomass burning, J. Geophys. Res.-Atmos., 119, 2014JD021750, https://doi.org/10.1002/2014JD021750, 2014.

McMurry, P. H., Wang, X., Park, K., and Ehara, K.: The relationship between mass and mobility for atmospheric particles: a new technique for measuring particle density, Aerosol Sci. Technol., 36, 227-238, https://doi.org/10.1080/027868202753504083, 2002.

Moffet, R. C., Qin, X. Y., Rebotier, T., Furutani, H., and Prather, K. A.: Chemically segregated optical and microphysical properties of ambient aerosols measured in a single-particle mass spectrometer, J. Geophys. Res.-Atmos., 113, D12213, https://doi.org/10.1029/2007jd009393, 2008.

Naeher, L. P., Brauer, M., Lipsett, M., Zelikoff, J. T., Simpson, C. D., Koenig, J. Q., and Smith, K. R.: Woodsmoke health effects: a review, Inhal. Toxicol., 19, 67-106, https://doi.org/10.1080/08958370600985875, 2007.

Nakayama, T., Ikeda, Y., Sawada, Y., Setoguchi, Y., Ogawa, S., Kawana, K., Mochida, M., Ikemori, F., Matsumoto, K., and Matsumi, Y.: Properties of light-absorbing aerosols in the Nagoya urban area, Japan, in August 2011 and January 2012: Contributions of brown carbon and lensing effect, J. Geophys. Res.-Atmos., 119, 12721-12739, https://doi.org/10.1002/2014jd021744, 2014.

Onasch, T. B., Massoli, P., Kebabian, P. L., Hills, F. B., Bacon, F. W., and Freedman, A.: Single scattering albedo monitor for airborne particulates, Aerosol Sci. Technol., 49, 267-279, https://doi.org/10.1080/02786826.2015.1022248, 2015.

Park, R., Jacob, D., Kumar, N., and Yantosca, R.: Regional visibility statistics in the United States: Natural and transboundary pollution influences, and implications for the Regional Haze Rule, Atmos. Environ., 40, 5405-5423, https://doi.org/10.1016/j.atmosenv.2006.04.059, 2006.

Petters, M. D., Carrico, C. M., Kreidenweis, S. M., Prenni, A. J., DeMott, P. J., Collett, J. L., and Moosmuller, H.: Cloud condensation nucleation activity of biomass burning aerosol, J. Geophys. Res.-Atmos., 114, D22205, https://doi.org/10.1029/2009jd012353, 2009.

Philippin, S., Wiedensohler, A., and Stratmann, F.: Measurements of non-volatile fractions of pollution aerosols with an eight-tube volatility tandem differential mobility analyzer (VTDMA-8), J. Aerosol Sci., 35, 185-203, https://doi.org/10.1016/j.jaerosci.2003.07.004, 2004.

Pitz, M., Schmid, O., Heinrich, J., Birmili, W., Maguhn, J., Zimmermann, R., Wichmann, H. E., Peters, A., and Cyrys, J.: Seasonal and diurnal variation of PM2.5 apparent particle density in urban air in Augsburg, Germany, Environ. Sci. Technol., 42, 5087-5093, https://doi.org/10.1021/es7028735, 2008.

Rissler, J., Nordin, E. Z., Eriksson, A. C., Nilsson, P. T., Frosch, M., Sporre, M. K., Wierzbicka, A., Svenningsson, B., Londahl, J., Messing, M. E., Sjogren, S., Hemmingsen, J. G., Loft, S., Pagels, J. H., and Swietlicki, E.: Effective density and mixing state of aerosol particles in a near-traffic urban environment, Environ. Sci. Technol., 48, 6300-6308, https://doi.org/10.1021/es5000353, 2014. 
Saleh, R., Robinson, E. S., Tkacik, D. S., Ahern, A. T., Liu, S., Aiken, A. C., Sullivan, R. C., Presto, A. A., Dubey, M. K., Yokelson, R. J., Donahue, N. M., and Robinson, A. L.: Brownness of organics in aerosols from biomass burning linked to their black carbon content, Nat. Geosci., 7, 647-650, https://doi.org/10.1038/ngeo2220, 2014.

Schmid, O., Karg, E., Hagen, D. E., Whitefield, P. D., and Ferron, G. A.: On the effective density of non-spherical particles as derived from combined measurements of aerodynamic and mobility equivalent size, J. Aerosol Sci., 38, 431-443, https://doi.org/10.1016/j.jaerosci.2007.01.002, 2007.

Schnaiter, M., Linke, C., Mohler, O., Naumann, K. H., Saathoff, H., Wagner, R., Schurath, U., and Wehner, B.: Absorption amplification of black carbon internally mixed with secondary organic aerosol, J. Geophys. Res.-Atmos., 110, D19204, https://doi.org/10.1029/2005jd006046, 2005.

Silva, P. J., Liu, D. Y., Noble, C. A., and Prather, K. A.: Size and chemical characterization of individual particles resulting from biomass burning of local Southern California species, Environ. Sci. Technol., 33, 3068-3076, https://doi.org/10.1021/es980544p, 1999.

Song, X. H., Hopke, P. K., Fergenson, D. P., and Prather, K. A.: Classification of single particles analyzed by ATOFMS using an artificial neural network, ART-2A, Anal. Chem., 71, 860-865, https://doi.org/10.1021/ac9809682, 1999.

Spencer, M. T., Shields, L. G., and Prather, K. A.: Simultaneous measurement of the effective density and chemical composition of ambient aerosol particles, Environ. Sci. Technol., 41, 13031309, https://doi.org/10.1021/es061425+, 2007.
Tajima, N., Fukushima, N., Ehara, K., and Sakurai, H.: Mass range and optimized operation of the aerosol particle mass analyzer, Aerosol Sci. Technol., 45, 196-214, https://doi.org/10.1080/02786826.2010.530625, 2011.

Turpin, B. J. and Lim, H.-J.: Species contributions to PM2.5 mass concentrations: revisiting common assumptions for estimating organic mass, Aerosol Sci. Technol., 35, 602-610, https://doi.org/10.1080/02786820119445, 2001.

Wentzel, M., Gorzawski, H., Naumann, K. H., Saathoff, H., and Weinbruch, S.: Transmission electron microscopical and aerosol dynamical characterization of soot aerosols, J. Aerosol Sci., 34, 1347-1370, https://doi.org/10.1016/s0021-8502(03)003604, 2003.

Zauscher, M. D., Wang, Y., Moore, M. J. K., Gaston, C. J., and Prather, K. A.: Air Quality Impact and Physicochemical Aging of Biomass Burning Aerosols during the 2007 San Diego Wildfires, Environ. Sci. Technol., 47, 7633-7643, https://doi.org/10.1021/es4004137, 2013.

Zhai, J., Wang, X., Li, J., Xu, T., Chen, H., Yang, X., and Chen, J.: Thermal desorption single particle mass spectrometry of ambient aerosol in Shanghai, Atmos. Environ., 123, 407-414, https://doi.org/10.1016/j.atmosenv.2015.09.001, 2015.

Zhang, R., Khalizov, A. F., Pagels, J., Zhang, D., Xue, H., and McMurry, P. H.: Variability in morphology, hygroscopicity, and optical properties of soot aerosols during atmospheric processing, P. Natl. Acad. Sci. USA, 105, 10291-10296, https://doi.org/10.1073/pnas.0804860105, 2008. 